\title{
Mondor's disease in a patient after a mammotome biopsy
}

\author{
Wojciech Kibil, Diana Hodorowicz-Zaniewska, Jan Kulig \\ First Chair of General, Oncological, and Gastrointestinal Surgery, Jagiellonian University Medical College, Krakow, Poland
}

Videosurgery Miniinv 2015; 10 (1): 138-140

DOI: $10.5114 /$ wiitm.2015.49095

\begin{abstract}
Mondor's disease is a rare, benign condition characterised by thrombophlebitis affecting subcutaneous veins of the chest and/or abdomen without an accompanying inflammatory response. The disease has a multifactorial etiology and its course is benign. It is usually self-limiting or it is eliminated by local treatment. Mondor's disease in the thoracoepigastric region may be a rare complication of mammotome biopsy. The case presentation describes a 32-yearold patient with Mondor's disease in the thoracoepigastric region after an ultrasound-guided mammotome biopsy of a breast. In the histopathological examination the lesion was diagnosed as fibroadenoma. Regardless of the disease's etiology, it is recommended to carry out diagnostic examinations to exclude co-occurring breast cancer.
\end{abstract}

Key words: Mondor's disease, superficial thrombophlebitis, mammotome biopsy.

\section{Introduction}

Mondor's disease is a rare condition characterised by thrombophlebitis affecting subcutaneous veins of the chest and/or abdomen without an accompanying inflammatory response. The course of the disease is benign; the condition tends to be self-limiting and to heal spontaneously. It was first described by Faage in 1869 as a kind of scleroderma - a chronic skin disease. Only in 1939 was it recognised as a separate disease by a French surgeon, Henri Mondor. Since then the disease has taken his name [1]. This paper describes the case of a patient with Mondor's disease in the thoracoepigastric region after an ultrasound-guided mammotome biopsy of a breast.

\section{Case report}

A 32-year-old patient underwent an ultrasoundguided mammotome biopsy of a solid lesion located in the superior lateral quadrant of the left breast. It was a single, well-delineated $12 \times 10 \mathrm{~mm}$ lesion, and it was classified as BI-RADS 4a. A follow-up mammogram was not performed due to the young age of the patient and the dense glandular tissue of the breast. The lesion was removed during the biopsy. In the histopathological examination the lesion was diagnosed as fibroadenoma.

The patient came to the clinic on the $7^{\text {th }}$ day after the procedure due to an ongoing, severely painful, cord-like induration on the skin on the left side of the thoracoepigastric region. She did not report fever or a history of co-existing diseases, bleeding disorders, breast trauma (apart from the biopsy) or intensive physical activity. She did not take any medications on a regular basis. A physical examination revealed painful, linear induration spreading from the inferior lateral quadrant of the left breast through the area under the left ribs to the wing of the ilium, which is consistent with the anatomical location of the thoracoepigastric vein. The lesion was particularly visible when the left arm was raised. The skin was not red or warm. The blood pressure was $125 / 75 \mathrm{~mm} \mathrm{Hg}$, the pulse 84 beats per minute, while the tempera-

\section{Address for correspondence}

Wojciech Kibil MD, PhD, First Chair of General, Oncological, and Gastrointestinal Surgery, Jagiellonian University Medical College,

40 Kopernika St, 31-501 Krakow, Poland, phone: +48 600667 739, fax: +48 1242480 07, e-mail: wkibil@op.pl 
ture was $36.6^{\circ} \mathrm{C}$. A Doppler ultrasound examination detected deteriorated blood flow in the altered vessel. Symptoms subsided after 6 days of application of heparin ointment. In order to exclude the possibility of other breast pathology, especially cancer, a follow-up magnetic resonance imaging examination was performed after 30 days, which showed only scar tissue after the biopsy. Follow-up ultrasound examinations after 6 and 12 months showed no recurrence of fibroadenoma or new focal lesions.

\section{Discussion}

Lesions in Mondor's disease are usually found on thoracoepigastric veins and lateral thoracic veins. They are less common on inferior epigastric veins or superficial veins of the breast. Lesions are rarely found on the penis, upper arms, arm pits or the groin area [2]. The disease is also know as superficial thrombophlebitis. It usually affects middle-aged women aged 30 to 60 .

The etiology of the disease is not well known. It is believed that the most common causes include mechanical trauma; surgery of the chest, abdomen, or the breast; vascular malformations, pregnancy, central line insertion, severe dehydration, use of vasoconstrictor drugs, intensive physical activity, infections, wearing too tight clothing and tight bandaging of the chest [2]. The disease sometimes co-occurs with breast cancer, especially inflammatory type [3]. However, in many cases the cause remains unclear. The main symptom of Mondor's disease is painful induration under the skin which runs along a blood vessel. When the arms are raised, a longitudinal groove can be seen. An ultrasound examination allows confirmation of the disease and exclusion of external pressure on the vessel. The altered vessel is visible in the form of a superficially located, longitudinal, anechoic lesion which looks like rosary beads, without blood flow in a Doppler ultrasound examination [4]. Within the breast, detected lesions are usually longer than milk ducts (up to $30 \mathrm{~mm}$ ), and they are most often located in the superior lateral quadrants of the breast. Diagnosis is based on association of clinical symptoms, the etiological factor and an ultrasound examination. It is not necessary to perform any other examinations in order to diagnose the disease. The differential diagnosis includes subacute phlebitis, nodular dermatitis, metastatic cancer of the skin or skin cancer infiltration, erythe- ma nodosum, lymphangiectasia, lymphangioma and drug-induced inflammation of veins. Mammograms usually do not detect lesions, although sometimes a rope-like shade is visible. However, a mammogram is recommended to exclude cancer [5]. In blood tests coagulopathy is evaluated. Treatment depends on the advancement of the observed lesions. In a majority of cases the symptoms subside spontaneously within 2 to 6 weeks. They are most often treated with non-steroidal anti-inflammatory drugs and heparin ointment. Some doctors recommend low molecular weight heparin [6-8]. With general symptoms, fever and leukocytosis it is recommended to administer an antibiotic. Sometimes, when symptoms last longer, it is necessary to remove the blood clot or perform a subcutaneous excision of the altered vein [9]. Mondor's disease rarely occurs in patients with breast diseases, but it should be remembered that it may be related to occurrence of breast cancer [3, 10, 11]. The disease sporadically occurs after surgical procedures performed in this area of the body.

In recent years the vacuum-assisted core biopsy is increasingly common because it is an efficient and minimally invasive procedure to diagnose and treat focal lesions in the breast [12]. That is why Mondor's disease in patients who underwent this procedure may be observed more frequently. Although the described case had well-documented etiology, we believe that it was not permissible to refrain from supplementary diagnostic examinations to exclude cancer. With glandular breast tissue or diagnostic uncertainty in the mammogram or ultrasound examinations, magnetic resonance imaging should be considered.

\section{Conclusions}

Mondor's disease in the thoracoepigastric region may be a rare complication of mammotome biopsy. Regardless of the disease's etiology, it is recommended to carry out diagnostic examinations to exclude co-occurring breast cancer.

\section{Conflict of interest}

The authors declare no conflict of interest.

\section{References}

1. Mondor H. Tronculite sous-cutanee subaigue de la panoi thoracique antero-laterale. Mem Acad Chir 1939; 65: 1271-8.

2. Fietta P, Manganelli P. Mondor's diseases. Spectrum of the clinical and pathological features. Minerva Med 2002; 93: 453-6. 
3. Paniagua CT, Negron ZD. Mondor's disease: a case study. J Am Acad Nurse Pract 2010; 22: 312-5.

4. Mahesh KS, Alfred BW. Mondor's disease of the breast: sonographic and mammographic findings. AJR 2000; 177: 893-6.

5. Conant EF, Wilkes AN, Mendelson EB, et al. Superficial thrombophlebitis of the breast (Mondor's disease): mammographic findings. AJR Am J Roentgenol 1993; 160: 1201-3.

6. Belleflamme M, Penaloza A, Thoma M, et al. Mondor disease: a case report in ED. Am J Emerg Med 2012; 30: 1325e1-3.

7. Cesarone MR, Belcaro G, Corsi M, et al. Local heparin, superficial vein thrombosis. Angiology 2007; 58: 36S-41S.

8. Viana GA, Okano FM. Superficial thrombophlebitis (Mondor's disease) after breast augmentation surgery. Indian J Plast Surg 2008; 41: 219-21.

9. Alvarez-Garrido H, Garrido-Ríos AA, Sanz-Muñoz C, et al. Mondor's disease. Clin Exp Dermatol 2009; 34: 753-6.

10. Catania S, Zurrida S, Veronesi P, et al. Mondor's disease and breast cancer. Cancer 1992; 69: 2267-70.

11. Vincenza Polito M, De Cicco P, Apicella R. Tight bra in a 34-yearold woman: an unusual cause of Mondor's disease. Ann Vasc Dis 2014; 7: 149-51.

12. Kibil W, Hodorowicz-Zaniewska D, Szczepanik A, Kulig J. Ultrasound-guided vacuum-assisted core biopsy in the diagnosis and treatment of focal lesions of the breast - own experience. Videosurgery Miniinv 2013; 8: 63-8.

Received: 1.09.2014, accepted: 24.12.2014 